\title{
Alcohol consumption, blood alcohol concentration level and guideline compliance in hospital referred patients with minimal, mild and moderate head injuries
}

Marianne Efskind Harr ${ }^{1,2^{*}}$, Ben Heskestad ${ }^{1,2,3}$, Tor Ingebrigtsen ${ }^{4}$, Bertil Romner ${ }^{4,5}$, Pål Rønning ${ }^{1}$ and Eirik Helseth ${ }^{1,2}$

\begin{abstract}
Background: In 2000 the Scandinavian Neurotrauma Committee published guidelines for safe and cost-effective management of minimal, mild and moderate head injured patients.

The aims of this study were to investigate to what extent the head injury population is under the influence of alcohol, and to evaluate whether the physicians' compliance to the guidelines is affected when patients are influenced by alcohol.
\end{abstract}

Methods: This study included adult patients ( $\geq 15$ years) referred to a Norwegian University Hospital with minimal, mild and moderate head injuries classified according to the Head Injury Severity Scale (HISS). Information on alcohol consumption was recorded, and in most of these patients blood alcohol concentration (BAC) was measured. Compliance with the abovementioned guidelines was registered.

Results: The study includes 860 patients. 35.8\% of the patients had consumed alcohol, and $92.1 \%$ of these patients had a BAC $\geq 1.00 \%$. Young age, male gender, trauma occurring during the weekends, mild and moderate head injuries were independent factors significantly associated with being under the influence of alcohol. Guideline compliance was $60.5 \%$, and over-triage was the main violation. The guideline compliance showed no significant correlation to alcohol consumption or to BAC-level.

Conclusions: This study confirms that alcohol consumption is common among patients with head injuries. The physicians' guideline compliance was not affected by the patients' alcohol consumption, and alcohol influence could therefore not explain the low guideline compliance.

\section{Background}

Traumatic brain injury (TBI) is the most common cause of death and permanent disability in trauma patients [1-3]. The incidence of TBI varies between different countries and studies [4]. The incidence for hospital referred and fatal TBIs in Europe and the United States is reported to be in the range of 83.3 - 403/100 000 and $15-18 / 100000$, respectively [3,5-8]. Various studies have shown that $16-51 \%$ of the patients admitted for TBIs are under the influence of alcohol [9-12].

\footnotetext{
* Correspondence: marianne.efskind@gmail.com

'Department of Neurosurgery, Oslo University Hospital - Ullevål,

P.O. Box 4950 Nydalen, N-0424 Oslo, Norway

Full list of author information is available at the end of the article
}

In year 2000 the Scandinavian Neurotrauma Committee (SNC) published guidelines with regards to safe and cost-effective management of minimal, mild and moderate head injured patients classified according to the Head Injury Severity Scale (HISS) [13,14]. Compliance to these guidelines has been far from complete $[15,16]$. Over-triage with either unnecessary hospital admission and/or CT-scanning was the main violation resulting in a cost increase for the health care provider. A possible explanation for the low guideline compliance with a substantial over-triage could be the frequent alcohol influence in this patient population. However, the relationship between alcohol consumption and compliance to these guidelines has so far not been studied.

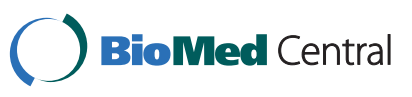

(c) 2011 Harr et al; licensee BioMed Central Ltd. This is an Open Access article distributed under the terms of the Creative Commons Attribution License (http://creativecommons.org/licenses/by/2.0), which permits unrestricted use, distribution, and reproduction in any medium, provided the original work is properly cited. 
The purpose of this study has been to investigate to what extent patients with minimal, mild and moderate head injuries are under influence of alcohol, and if alcohol consumption affects how these patients are managed according to the SNC guidelines.

\section{Methods}

This study is based on data collected from Stavanger University Hospital, a hospital located in the southwestern part of Norway with a catchment population of 320 000. A search was made in the hospital's electronic medical charts for patients registered with ICD-10 codes involving head injuries referred to the hospital from January through June in the years 2005, 2007 and 2009. Adult patients ( $\geq 15$ years) with minimal, mild or moderate head injuries according to the Head Injury Severity Scale, HISS, were included in the study [14]. The medical record for each patient was retrospectively reviewed and patient information registered in a database.

The recorded patient information included:

a. date of birth, trauma date and gender

b. Glasgow Coma Scale (GCS) score on admission [17]

c. amnesia (yes or no)

d. HISS score (minimal, mild, moderate) [14]

e. hospitalization for overnight observation (yes or no)

f. risk factors present according to SNC guidelines (yes or no) [13]

g. head CT performed (yes or no)

h. related pathological findings on head CT (yes or no)

i. hospitalization required for reasons other than the actual head injury (yes or no)

j. compliance according to SNC guidelines (yes, no over-triage with unnecessary CT scan, no - overtriage with unnecessary admission for overnight observation, no - over-triage with both unnecessary CT scan and admission or no - under-triage with CT scan not taken and/or not admitted for overnight observation)

k. weekday of admission

1. alcohol consumption (yes (self-reported, patients clinically judged to be under the influence of alcohol by the admitting physician or blood alcohol concentration $>0$ ) or no)

$\mathrm{m}$. in the majority of patients who were judged to be under influence of alcohol based on clinical evaluation and/or reported that they had consumed alcohol, the blood alcohol concentration (BAC) in promille (grams of alcohol per kilogram of blood) was measured on admission.

For statistical analysis variables were checked for normality graphically using quantile-quantile plots and analytically using the Shapiro-wilks test. We used a combination of robust independent $\mathrm{t}$-samples tests, chi squared tests and Wilcoxon tests to check if groups where equal. Univariate and multivariate logistic regression was used after dichotomizing the dependent variables. Age, gender, HISS score, weekday of admission, alcohol consumption and BAC were included as covariates in the multivariate logistic regression models. In case of missing values we discarded the entire observation for the multivariate analyses. The resulting coefficients were exponentiated to obtain odds-ratios. Confidence intervals were calculated. A p-value less than 0.05 was considered statistically significant. $\mathrm{R} \mathrm{v}$ 11.1 was used for statistical analyses [18].

\section{Results}

\section{Patients}

This study includes 860 adult patients with minimal, mild and moderate TBI, giving an estimated annual incidence of 179/100 000. The mean age was 40.9 years (range 15 99 years) and $66.6 \%$ were men. The mean age of men included in this study was significantly lower than the mean age of women (Mann-Whitney U test, $\mathrm{p}<0.001)$. According to HISS, $12.8 \%$ (110/860) had a minimal TBI, $71.4 \%(614 / 860)$ had a mild TBI and $15.8 \%$ (136/860) had a moderate TBI. Table 1 shows a summary of the patient characteristics.

\section{Alcohol consumption}

At time of admission, 35.8\% (308/860) had consumed alcohol (Table 1). Using univariate and multivariate analysis we found that young age, male gender, trauma occurring during the weekends and mild and moderate TBIs were independent factors significantly associated with alcohol consumption (Table 2).

\section{Blood alcohol concentration}

The blood alcohol concentration (BAC) was measured in $87 \%(267 / 308)$ of the patients which reported that they had consumed alcohol and/or were clinically judged by the admitting physician to be under the influence of alcohol. All 267 BACs measured were above 0, with a minimum value of $0.10 \%$ and a maximum value of $4.70 \%$. Of these, $7.9 \%(21 / 267)$ had a BAC in the range $0.10-0.99 \%$, 30.3\% (81/267) had BAC 1.00-1.99\%o and $61.8 \%(165 / 267)$ had BAC $\geq 2.00 \%$. The mean BAC in the patients being under influence was $2.14 \%$. The mean BAC was $2.04 \%$ for women and $2.17 \%$ o for men, which is not significantly different (independent samples t-test, $\mathrm{p}=0.29$ ).

\section{SNC guideline compliance}

The overall compliance to the guidelines was $60.5 \%$ (520/860). Among the 340 patients not managed 
Table 1 Patient characteristics $(n=860)$

\begin{tabular}{|c|c|c|c|c|c|}
\hline & & \multirow{2}{*}{$\begin{array}{c}\text { Overall } \\
\mathrm{N}=860\end{array}$} & \multicolumn{2}{|c|}{ Gender } & \multirow[t]{2}{*}{ Test statistic } \\
\hline & & & $\begin{array}{l}\text { Female } \\
\mathrm{N}=287\end{array}$ & $\begin{array}{c}\text { Male } \\
N=573\end{array}$ & \\
\hline Age (years) & Median & 35.0 & 45.0 & 32.0 & $F_{1,858}=30.51, P<0.001^{2}$ \\
\hline \multirow[t]{4}{*}{ Age group (years) } & $15-24$ & $292(34.0 \%)$ & $83(28.9 \%)$ & $209(36.5 \%)$ & $\chi^{2}{ }_{3}=52.89, P<0.001^{3}$ \\
\hline & $25-39$ & $181(21.0 \%)$ & $42(14.6 \%)$ & $139(24.3 \%)$ & \\
\hline & $40-59$ & $205(23.8 \%)$ & $61(21.3 \%)$ & $144(25.1 \%)$ & \\
\hline & $\geq 60$ & $182(21.2 \%)$ & $101(35.2 \%)$ & $81(14.1 \%)$ & \\
\hline \multirow[t]{3}{*}{ HISS $^{1}$} & Minimal & $110(12.8 \%)$ & $54(18.8 \%)$ & $56(9.8 \%)$ & $\chi_{2}^{2}=16.14, P<0.001^{3}$ \\
\hline & Mild & $614(71.4 \%)$ & $198(69.0 \%)$ & $416(72.6 \%)$ & \\
\hline & Moderate & $136(15.8 \%)$ & $35(12.2 \%)$ & $101(17.6 \%)$ & \\
\hline \multirow[t]{2}{*}{ Alcohol consumption } & Yes & 308 (35.8\%) & $62(21.6 \%)$ & $246(42.9 \%)$ & $\chi^{2}{ }_{1}=37.84, P<0.001^{3}$ \\
\hline & No & $552(64.2 \%)$ & $225(78.4 \%)$ & $327(57.1 \%)$ & \\
\hline
\end{tabular}

${ }^{1}$ HISS - Head Injury Severity Scale [14].

${ }^{2}$ Wilcoxon test.

${ }^{3}$ Pearson test.

Table 2 Logistic regression analysis of variables possibly associated with increased probability of alcohol consumption

\begin{tabular}{|c|c|c|}
\hline Variable & $\begin{array}{l}\text { Univariate } \\
\text { Odds ratio }(95 \% \mathrm{Cl})\end{array}$ & $\begin{array}{l}\text { Multivariate } \\
\text { Odds ratio }(95 \% \mathrm{Cl})\end{array}$ \\
\hline Age & $\begin{array}{l}0.99^{* * *} \\
(0.98,0.99)\end{array}$ & $\begin{array}{l}0.98^{* * *} \\
(0.97,0.99)\end{array}$ \\
\hline \multicolumn{3}{|l|}{ Gender } \\
\hline Male & 1 & 1 \\
\hline Female & $\begin{array}{l}0.46^{* * *} \\
(0.32,0.66)\end{array}$ & $\begin{array}{l}0.37^{* * *} \\
(0.26,0.51)\end{array}$ \\
\hline \multicolumn{3}{|l|}{ HISS } \\
\hline Minimal & 1 & 1 \\
\hline Mild & $\begin{array}{l}4.84^{* * *} \\
(2.47,9.51)\end{array}$ & $\begin{array}{l}5.21^{* * *} \\
(2.73,9.91)\end{array}$ \\
\hline Moderate & $\begin{array}{l}9.03^{* * *} \\
(4.24,19.20)\end{array}$ & $\begin{array}{l}10.13^{* * *} \\
(5.00,20.55)\end{array}$ \\
\hline \multicolumn{3}{|l|}{ Day } \\
\hline Monday & 1 & 1 \\
\hline Tuesday & $\begin{array}{l}0.76 \\
(0.38,1.54)\end{array}$ & $\begin{array}{l}0.80 \\
(0.41,1.57)\end{array}$ \\
\hline Wednesday & $\begin{array}{l}0.72 \\
(0.37,1.42)\end{array}$ & $\begin{array}{l}0.82 \\
(0.43,1.55)\end{array}$ \\
\hline Thursday & $\begin{array}{l}0.71 \\
(0.35,1.44)\end{array}$ & $\begin{array}{l}0.76 \\
(0.39,1.50)\end{array}$ \\
\hline Friday & $\begin{array}{l}0.94 \\
(0.51,1.74)\end{array}$ & $\begin{array}{l}0.92 \\
(0.60,1.95)\end{array}$ \\
\hline Saturday & $\begin{array}{l}2.57^{* * *} \\
(1.47,4.49)\end{array}$ & $\begin{array}{l}3.18^{* * *} \\
(1.87,5.40)\end{array}$ \\
\hline Sunday & $\begin{array}{l}3.24 * * * \\
(1.86,5.67)\end{array}$ & $\begin{array}{l}3.85^{* * *} \\
(2.27,6.52)\end{array}$ \\
\hline
\end{tabular}

according to the guidelines, 88.2\% (300/340) underwent over-triage and $11.8 \%$ (40/340) under-triage. In minimal, mild and moderate head injuries according to HISS the compliance were $45.5 \%, 54.9 \%$ and $97.8 \%$, respectively. Using univariate and multivariate analysis we found that old age and moderate TBI were independent variables significantly associated with higher compliance rate (Table 3, Table 4). Neither gender nor alcohol influence nor BAC-level showed significant correlation with guideline compliance.

Table 3 Logistic regression analysis of variables possibly associated with increased probability of guideline compliance

\begin{tabular}{lll}
\hline Variable & $\begin{array}{l}\text { Univariate } \\
\text { Odds ratio }(\mathbf{9 5 \%} \mathbf{C l})\end{array}$ & $\begin{array}{l}\text { Multivariate } \\
\text { Odds ratio }(\mathbf{9 5 \%} \mathbf{~ C l})\end{array}$ \\
\hline Alcohol consumption & & 1 \\
No & 1 & 0.92 \\
Yes & $0.67^{*}$ & $(0.69,1.22)$ \\
\hline Age & $(0.49,0.93)$ & $1.01^{* * *}$ \\
& $1.01^{* *}$ & $(1.01,1.02)$ \\
\hline Gender & $(1.00,1.02)$ & \\
Male & & 1 \\
Female & 1 & 0.87 \\
& 0.84 & $(0.65,1.16)$ \\
\hline HISS & $(0.61,1.16)$ & \\
Minimal & & 1 \\
Mild & 1 & 1.46 \\
Moderate & $1.61^{*}$ & $(0.97,2.20)$ \\
& $(1.05,2.45)$ & $53.20^{* * *}$ \\
\hline
\end{tabular}




\begin{tabular}{|c|c|c|}
\hline Variable & $\begin{array}{l}\text { Univariate } \\
\text { Odds ratio }(95 \% \mathrm{Cl})\end{array}$ & $\begin{array}{l}\text { Multivariate } \\
\text { Odds ratio }(95 \% \mathrm{Cl})\end{array}$ \\
\hline BAC & $\begin{array}{l}0.93 \\
(0.65,1.35)\end{array}$ & $\begin{array}{l}1.30 \\
(0.96,1.75)\end{array}$ \\
\hline Age & $\begin{array}{l}1.01 \\
(1.00,1.03)\end{array}$ & $\begin{array}{l}1.01 * * * \\
(1.01,1.02)\end{array}$ \\
\hline \multicolumn{3}{|l|}{ Gender } \\
\hline Male & 1 & 1 \\
\hline Female & $\begin{array}{l}0.84 \\
(0.42,1.66)\end{array}$ & $\begin{array}{l}0.87 \\
(0.65,1.16)\end{array}$ \\
\hline \multicolumn{3}{|l|}{ HISS } \\
\hline Minimal & 1 & 1 \\
\hline Mild & $\begin{array}{l}1.78 \\
(0.42,7.54)\end{array}$ & $\begin{array}{l}1.46 \\
(0.97,2.20)\end{array}$ \\
\hline Moderate & $\begin{array}{l}146.04^{* * *} \\
(12.64,1687.30)\end{array}$ & $\begin{array}{l}53.20^{* * *} \\
(15.96,177.38)\end{array}$ \\
\hline
\end{tabular}

*** $\mathrm{P}<0.001,{ }^{* *} \mathrm{P}<0.01,{ }^{*} \mathrm{P}<0.05$.

\section{Discussion}

This study confirms that alcohol consumption is common among patients with head injuries, and it shows that physician's guideline compliance is not affected by patients' alcohol consumption. Furthermore, we found that young age, male gender, trauma occurring during the weekends, mild and moderate TBIs were independent factors significantly associated with alcohol consumption.

The incidence of minimal, mild and moderate head injuries referred to hospital was estimated to 179/100 000, which is comparable to other studies reporting incidence levels in the range of $83.3-403 / 100000$ [3,5-8]. We report that the majority of the head injured patients were men (66.6\%), and that most patients (34\%) were aged 15-24. The majority of the patients, both those who had and had not consumed alcohol, were classified with a mild head injury. These findings are in line with the results from other studies of hospital referred head injuries $[4,6-8,19]$.

We report that $35.8 \%$ of the patients had consumed alcohol at the time of admission. For traumas in general, it has been reported that $4-45 \%$ of injured patients are under the influence of alcohol [12,20,21]. With regards to traumatic brain injuries, alcohol use has been reported to be involved in $16-51 \%$ of these injuries [9-12].

Among the patients having consumed alcohol, 7.9\% had a BAC lower than $1.00 \%, 30.3 \%$ had a BAC between $1.00-1.90 \%$ and $61.8 \%$ a BAC at or greater than $2.00 \%$. The mean BAC was 2.14\%. Moskowitz reports that impairment in behavior, visual functions and body balance have been demonstrated at blood alcohol concentrations of $0.30-0.40 \%$ [22]. Increasing BAC aggravates these effects of alcohol [23]. Alcohol consumption resulting in intoxication might alter judgment, cause a more risk taking behavior, and impair motor and sensor functions, which can make people prone to head injuries.

Increasing levels of BACs can affect a person's memory [23] and cause amnesia, which could alter the classification of a head injury as defined in HISS $[23,14]$. There is a lower proportion of minimal head injury among the patients that had consumed alcohol than in those who had not. In the patient group being under the influence of alcohol, mild and moderate head injuries were more common. These findings might suggest that influenced patients can get lower GCS scores, and/ or more often report loss of consciousness than the non-indulgent patients, which both will alter the HISS grade. However, firm evidence for reduction of GCS in trauma patients by alcohol is lacking. Thus, attributing low GCS to alcohol intoxication in TBI patients may delay necessary diagnostic and therapeutic interventions [24-26].

Guidelines are made in hope to secure safe, high quality and cost-effective patient management. Compliance to such guidelines is often low, as has been the case for the SNC-guidelines $[15,16]$. We report an overall guideline compliance of $60.5 \%$, and that the main violation was over-triage. Alcohol consumption among the patients did not change the physicians' decision making with regards to guideline compliance. We found that the compliance rate was significantly higher for patients with moderate TBI than for patients with minimal or mild TBI, as has been shown by Heskestad et al. earlier [16].

This study has limitations. The study design was retrospective. The patients included were selected by general practitioners for hospital referral. The blood alcohol concentration was not measured in all relevant patients.

\section{Conclusions}

This study confirms that alcohol consumption is common among patients with head injuries. Most of the patients who had consumed alcohol had blood alcohol concentrations at intoxication levels (BAC $\geq 1.00 \%$ ). The physician's guideline compliance was not affected by the patient's alcohol consumption. Alcohol consumption cannot explain the low guideline compliance.

\section{Author details}

'Department of Neurosurgery, Oslo University Hospital - Ullevål, P.O. Box 4950 Nydalen, N-0424 Oslo, Norway. ${ }^{2}$ Faculty of Medicine, University of Oslo, P.O. Box 1018 Blindern, N-0315 Oslo, Norway. ${ }^{3}$ Department of Neurosurgery, Stavanger University Hospital, P.O. Box 8100, N-4068 Stavanger, Norway. ${ }^{4}$ Department of Neurosurgery, Faculty of Health Sciences, Institute for Clinical Medicine, University of Tromsø, and University Hospital of North Norway, P.O. Box 6060, N-9038 Tromsø, Norway. ${ }^{5}$ Department of Neurosurgery, Rigshospitalet, Blegdamsvej 9, DK-2100 Copenhagen $\varnothing$, Denmark. 


\section{Authors' contributions}

MEH was involved in the study design, gathered data, and drafted the manuscript. $\mathrm{BH}$ took part in the study design and gathering of data and helped draft the manuscript. TI participated in the study design and helped drafting the manuscript. BR participated in the study design and helped drafting the manuscript. PR did all statistical analysis and helped to draft the manuscript. EH contributed to the design of the study, data gathering and helped to draft the manuscript. All authors have read and approved the final manuscript.

\section{Competing interests}

The authors declare that they have no competing interests.

Received: 15 February 2011 Accepted: 17 April 2011

Published: 17 April 2011

\section{References}

1. Thurman DJ, Guerrero J, Sniezek JE: Traumatic Bain Injury in the United States: A Public Health Perspective. J Head Trauma Rehabil 1999, 14:602-615.

2. Ghajar J: Traumatic brain injury. Lancet 2000, 356:923-929.

3. Tagliaferri F, Compagnone C, Korsic M, Kraus J: A systemic review of brain injury epidemiology in Europe. Acta Neurochir (Wien) 2008, 148:255-268.

4. Jennett B: Epidemiology of head injury. J Neurol Neurosurg Psychiatry 1996, 60:362-369.

5. Andelic N, Sigurdardottir S, Brunborg C, Roe C: Incidence of hospitaltreated traumatic brain injury in the Oslo population. Neuroepidemiology 2008, 30:120-128.

6. Ingebrigtsen T, Mortensen K, Romner B: The epidemiology of hospitalreferred head injury in northern Norway. Neuroepidemiology 1998, 17:139-146.

7. Heskestad B, Baardsen R, Helseth E, Ingebrigtsen T: Guideline compliance in management of mild head injury: High frequency of non-compliance among individual physicians despite strong guideline support from clinical leaders. J Trauma 2008, 65:1309-1313.

8. Corrigan JD, Selassie AW, Orman JA: The epidemiology of traumatic brain injury. J Head Trauma Rehabil 2010, 25:72-80.

9. Parry-Jones BL, Vaughan FL, Miles CW: Traumatic brain injury and substance misuse: a systematic review of prevalence and outcomes research (1994-2004). Neuropsychol Rehabil 2006, 16:537-560.

10. Andelic N, Jerstad T, Sigurdardottir S, Schanke AK, Sandvik L, Roe C: Effects of acute substance use and pre-injury substance abuse on traumatic brain injury severity in adults admitted to a trauma centre. J Trauma Manag Outcomes 2010, 4:6.

11. Guruaj G: The effect of alchohol on incidence, pattern, severity and outcome from traumatic brain injury. J Indian Med Assoc 2004, 102:157-160, 163.

12. Levy DT, Mallonee S, Miller TR, Smith GS, Spicer RS, Romano EO, Fisher DA: Alcohol involvement in burn, submersion, spinal cord and brain injuries. Med Sci Monit 2004, 10:17-24.

13. Ingebrigtsen T, Romner B, Kock-Jensen C: Scandinavian guidelines for initial management of minimal, mild, and moderate head injuries. The Scandinavian Neurotrauma Committee. J Trauma 2000, 48:760-766.

14. Stein SC, Spettell C: The Head Injury Severity Scale (HISS): a practical classification of closed-head injury. Brain Inj 1995, 9:437-444.

15. Müller K, Waterloo K, Romner B, Wester K, Ingebrigtsen T: Mild head injuries: Impact of a national strategy for implementation of management guidelines. J Trauma 2003, 55:1029-1034.

16. Heskestad B, Baardsen R, Helseth E, Romner B, Waterloo K, Ingebrigtsen T: Incidence of hospital referred head injuries in Norway: a population based survey from the Stavanger region. Scand I Trauma Resusc Emerg Med 2009, 17:6.

17. Teasdale G, Jennett B: Assessment of coma and impaired consciousness. A practical scale. Lancet 1974, 304:81-84.

18. R Development Core Team: R: A language and environment for statistical computing. R Foundation for Statistical Computing, Vienna, Austria; 2010 [http://www.R-project.org], ISBN 3-900051-07-0.

19. Rickels $E$, von Wild K, Wenzlaff P: Head injury in Germany: A populationbased prospective study on epidemiology, causes, treatment and outcome of all degrees of head-injury severity in two distinct areas. Brain Inj 2010, 24:1491-1504.
20. World Health Organization, Department of Mental Health and Substance Abuse, Department of Injuries and Violence Prevention: Alcohol and Injury in Emergency Departments - Summary of the Report from the WHO Collaborative Study on Alcohol and Injuries. 2007 [http://www.who.int/ substance_abuse/publications/alcohol_injury_summary.pdf], ISBN 978924 1594851.

21. MacLeod JB, Hungerford DW: Alcohol-related injury visits: do we know the true prevalence in U.S. trauma centres? Injury 2010, 41:847-851.

22. Moskowitz H, Fiorentino D: A Review of the Literature on the Effects of Low Doses of Alcohol on Driving-Related Skills. Final Report. Prepared for U.S. Department of Transportation, National Highway Traffic Safety Administration; 2000 [http://www.nhtsa.gov/people/injury/research/pub/ Hs809028/Title.htm\#Contents].

23. Vonghia L, Leggio L, Ferulli A, Bertini M, Gasbarrini G, Addolorato G, Alcoholism Treatment Study Group: Acute alcohol intoxication. Eur J Intern Med 2008, 19:561-567.

24. Sperry JL, Genitello LM, Minei JP, Diaz-Arrastia RR, Friese RS, Shafi S: Waiting for the patient to "sober up": Effect of alcohol intoxication on glasgow coma scale score. J Trauma 2006, 61:1305-1311.

25. Stuke L, Diaz-Arrastia R, Gentilello LM, Shafi S: Effect of alcohol on Glasgow Coma Scale in head-injured patients. Ann Surg 2007, 245:651-655.

26. Lange RT, Iverson GL, Brubacher JR, Franzen MD: Effect of blood alcohol level on Glasgow Coma Scale scores following traumatic brain injury. Brain Inj 2010, 24:919-927.

\section{doi:10.1186/1757-7241-19-25}

Cite this article as: Harr et al: Alcohol consumption, blood alcohol concentration level and guideline compliance in hospital referred patients with minimal, mild and moderate head injuries. Scandinavian Journal of Trauma, Resuscitation and Emergency Medicine 2011 19:25.

\section{Submit your next manuscript to BioMed Central and take full advantage of:}

- Convenient online submission

- Thorough peer review

- No space constraints or color figure charges

- Immediate publication on acceptance

- Inclusion in PubMed, CAS, Scopus and Google Scholar

- Research which is freely available for redistribution

Submit your manuscript at www.biomedcentral.com/submit
C Biomed Central 